TECHNICAL REPORT

September 1, 1991, through November 30, 1991

\title{
Project Title: CFBC Evaluation of Fuels Processed from Illinois Coals
}

\section{Principal \\ Investigator: \\ Dr. S. Rajan \\ Mechanical Engineering and Energy Processes \\ Southern Illinois University \\ Carbondale, IL 62901}

Project Monitor: Dr. Ken Ho, CRSC
DE-FG22-91PC 91334

$\mathrm{DOE} / \mathrm{PC} / 91334--\mathrm{T} 7$

DE92 007885

\begin{abstract}
A number of "clean" fuels are being developed from Illinois high sulfur coal to promote its more widespread usage. Combustion evaluation of these new fuel forms is an important step linking process development and final marketing of these new fuels. Heat release data inferred from carbon conversion efficiencies, and the potential to meet $\mathrm{SO}_{2}$ emissions regulations with minimum sorbent utilization are to be demonstrated by combustion testing. Comparison of the combustion and emissions properties of these new fuels need to be compared with corresponding data from run-of-mine coal. Also, combustion evaluation of these new fuels can provide feedback data to the researchers on optimizing process parameters such that these clean fuels can have the best possible combustion characteristics while meeting $\mathrm{SO}_{2}$ and $\mathrm{NO}_{x}$ emissions requirements.

The fuels to be evaluated in this project are (a) flotation slurry samples beneficiated from coal fines containing $30 \%$ and $80 \%$ solids, and (b) coalsorbent pellets made from coal fines. Combustion data from these two fuels is to be compared with similar data obtained from a standard IBCSP coal. The tests are to be conducted in a 3 -inch, internal-diameter, refractory-1ined circulating fluidized bed combustor.

During this first quarter, progress has been made in establishing baseline data for comparing the performance of the new fuel forms with corresponding combustion data obtained from the standard IBCSP No. 5 coal. Some minor problems in the gas sampling equipment have been rectified. An Accu-Rate limestone feeder has been secured, mounted in position and calibrated. Standard coal and limestone samples have been acquired and size-graded. A malfunction problem with tile sulfur diaxide monitor has been remedied. Combustion testing with coal has been performed in the $3^{\prime \prime}$ diameter circulating fluidized bed combustor burning standard coal. Baseline data is being gathered for comparison with corresponding data to be obtained with the beneficiated slurry and coal-sorbent pellet fuels.
\end{abstract}

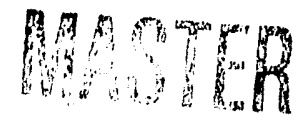

This project is funded by the U. S. Department of Energy (METC) and by the Illinois Department of Energy and Natural Resources as part of their costshared program. 


\section{EXECUT IVE SUMMARY.}

The goal of this research is to evaluate the combustion and emissions characteristics of two new fuels being developed under CRSC sponsorship. These fuels are (a) beneficiated flotation slurries processed from preparation plant feed from the Kerr-McGee Galatia plant and (b) coal-sorbent pellets containing $5-10 \%$ lime. Tests are also to be conducted under similar conditions with a standard IBCSP coal for comparison purposes. The combustor selected for testing is the 3 " internal diameter fuel tolerant circulating fluidized bed combustor. Parameters to be measured during the tests are the carbon conversion efficiency, $\mathrm{SO}_{2}$ and $\mathrm{NO}_{\mathrm{x}}$ emissions levels and the mineral matter composition of the residuat ash. Test parameters to be measured are the superficial velocity, bed temperature, $\mathrm{Ca} / \mathrm{S}$ ratio used, excess air ratio, etc. Details of the experimental procedures and the equipment are given in the body of the report.

This report covers the first quarter of this new project. During this quarter, the CFBC unit has been brought on-line following some equipment modifications and installation. In previous tests, the gas sampling line had a tendency to get clogged during prolonged periods of sampling. This condition has been rectified by installing an air flushing line. A check on the gas sampling analyzers revealed an electrical problem with the sulfur dioxide analyzer. This has been remedied to ensure proper operation of the $\mathrm{SO}_{2}$ analyzer. An Accu-Rate limestone feeder has been installed and calibrated. Pneumatic lines have been installed for limestone injection into the circulating fluidized bed combustor. The in-bed heat exchanger set-up has been modified to obtain better control of the bed temperature during operation. Coal, limestone and sand samples have been procured and size graded for experiment. A coal slurry feed system has been installed in readiness for slurry fuels testing.

The circulating fluidized bed combustor has been fired up on coal and all operating systems checked out. Tests are presently being conducted to secure baseline data with a standard coal. 


\section{OBJECTIVES}

The overall objectives for this one-year project are:

1. to demonstrate that new fuels derived from Illinois high sulfur coal, namely (a) coal-sorbent pellets and (b) coal-water slurry produced from froth flotation feed can be effectively utilized in a circulating fluidized bed combustor,

2. to compare the carbon conversion efficiencies, $\mathrm{SO}_{2}$ and $\mathrm{NO}_{x}$ emission levels and $\mathrm{Ca} / \mathrm{S}$ ratios needed to meet EPA regulations from the above fuels with those measured under similar operating conditions with a standard IBCSP coal, and

3. to analyze ash and spent limestone residues with a view to proposing waste disposal strategies for the combustion residues resulting from these new fuel forms.

The specific goals to be achiever as stated in the proposal are as follows:

1. determination of the carbon conversion efficiency of (a) the froth flotation coal water slurry fuel developed at the ISGS under CRSC sponsorship, and (b) the coal-sorbent pelletized fuel developed by ISGS under CRSC funding.

2. determination of the $\mathrm{Ca} / \mathrm{S}$ mole ratio requirements for the coal-water slurry fuel to meet $\mathrm{EPA} \mathrm{SO}_{2}$ emissions requirements.

3. determination of the sulfur capture efficiency of the coal-sorbent pellet fue 1

4. evaluation of the mineral matter elemental distribution in the combustion residues from the above fuels when burned in a laboratory scale 3 -inch internal diameter circulating fluidized bed combustor

5. determination of the $\mathrm{NO}_{x}$ emission levels when burning the coal-water slurry and the pelletized fuel in a CFBC unit

6. comparison of the carbon conversion efficiency, carbon balances, $\mathrm{SO}_{2}$ and $\mathrm{NO}$ emission levels and combustion waste analyses of the coal water slurry and pelletized fuel with equivalent values obtained from a standard IBCSP coal

The accomplishment of these goals involve the following tasks: (a) fuels procurement, (b) fuel testing and analysis, (c) fuels preparation, (d) installation of limestone feeder, (e) combustion testing in a three-inch internal diameter circulating fluidized bed combustor, $(f)$ combustion residues analys is using EDX, and $(\mathrm{g})$ data analysis and report preparation. 


\section{INTRODUCTION AND BACKGROUND}

Increased utilization of Illinois coals can be promoted by developing clean burning coal-based fuels which are low in sulfur and high in heating value. One such project, funded by CRSC, is aimed at developing coal-sorbent pellets from coal fines. A second CRSC supported project recovers fine coal from plant waste employing various flotation techniques, producing a slurry with higher solids concentration and Btu content. The market potential of these fuels will depend on the combustion and emissions characteristics of the coal/sorbent pellets and the coal slurry. This can be established only by combustion testing under conditions simulating actual boiler firing. Because of the small quantities of the fuels being produced, laboratory-scale combustors are best suited to demonstrate their utility and emissions characteristics.

There is a need to evaluate the burning characteristics of the coal-sorbent pellets and the coal water slurry to determine whether they can be burned easily and with good carbon conversion efficiencies. In the case of the coalsorbent pellets, it is necessary to quantitatively evaluate the sulfur capture efficiency of the pellets, in comparison with the case where the coal and sorbent are fed separately, to establish the merits of the coal-sorbent pelletization process. Additionally, it is necessary to investigate how the pelletization process, namely the mixing of the sorbent with the coal matrix influences the porosity and carbon burnout histories of the coal. The sorbent $\mathrm{Ca} / \mathrm{S}$ ratios needed to meet EPA requirements with the coal water slurry and its carbon conversion efficiency neers to be evaluated in comparison with standard Illinois coals to demonstrate the usefulness of the separation process.

The research currently being performed in this project addresses the above needs to improve the usefulness of fuels produced from high sulfur coals.

\section{EXPERIMENTAL PROCEDURES}

The experiments are being conducted in the 3-inch internal diameter circulating fluidized bed combustor shown schematically in Figure 1. The combustion testing of the coal slurry and pellet fuels involves the following steps:

* The $\mathrm{CO}, \mathrm{CO}_{2}, \mathrm{O}_{2}, \mathrm{NO}_{x}$ and $\mathrm{SO}_{2}$ analyzers are calibrated at the beginning and at several times during a test burn.

* The CFBC combustor is filled with the proper amount of bed material (sand or limestone).

* The propane preheat system is fired the bed material and unit is brought up to about $1100-1200^{\circ} \mathrm{F}$. This step takes several hours.

* Coal and limestone hoppers are filled with prepared standard coal and limestone sorbent, respectively.

* The coal feed is initiated and the CFBC unit is brought up to operating temperatures of around $1500^{\circ} \mathrm{F}$ on the standard coal. The operation of all sampling and control systems are checked. 


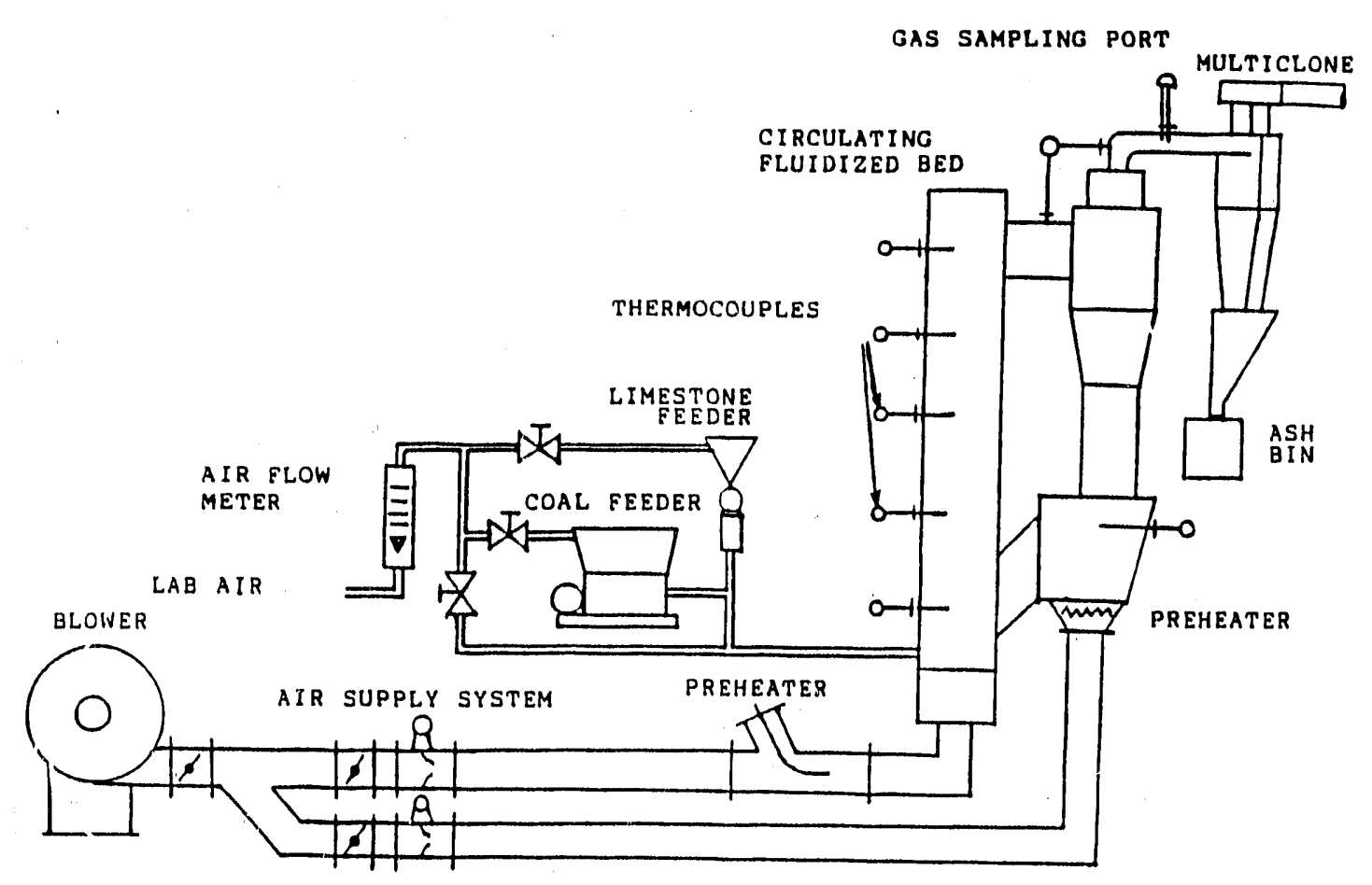

Figure 1. Schematic of 3" Diameter Circulating Fluidized Bed Facility Used for Fuels Testing 
* For tests with standard coal and the slurry and pellet fuels, typical values of operating variables are as follows:

$$
\begin{gathered}
\text { fluidization velocity } 7-10 \mathrm{ft} / \mathrm{sec} \\
\text { Ca/s ratio } 1-3 \\
\text { Excess air ratio } \approx 20 \% \\
\text { Bed temperature } \approx 1500^{\circ} \mathrm{F}
\end{gathered}
$$

These parameters are kept constant with all the fuels, so that comparison of the combustion and emissions parameters can be made under identical conditions of operation.

* During the coal-sorbent pellet tests, the pellets will be fed in the same manner as the standard coal. No additional limestone sorbent will be injected during initial tests. If $\mathrm{SO}_{2}$ emissions are higher than EPA limits, further tests will be conducted with limestone injection.

* With the coal-water slurry fuels, a special in-house fabricated pneumatic slurry injection system will be employed to inject the slurry fuel into the combustor.

* Six to ten test runs are planned to be made. Each test run is made after the combustor has reached steady state conditions. Combustor steady state conditions are usually achieved after 30-48 hours of operation. Where test fuel supplies are limited, the procedure adopted is to first bring the combustor to steady state operation on the standard coal or another Illinois coal, and then change the fuel feed to the test coal, slurry or pellet fuel only for the duration of the steady state data acquisition period.

* The variables measured during a test include

- fuel and air mass flows

- air superficial velocity

- bed temperature

- other temperatures at various combustor locations

- combustion gas analys is comprised of $\mathrm{CO}, \mathrm{CO}_{2}, \mathrm{O}_{2}, \mathrm{NO}_{X}$ and $\mathrm{SO}_{2}$ emissions

- test duration time

- quantity of ash collected in cyclones during test period

Combustion generated ash and spent limestone from the slurry fuel, pellets and standard coal tested will be analyzed. The heat content of the elutriated unburnt carbon will be determined from calorimetry tests. Spent limestone and ash will be prepared on metal stubs and subjected to energy dispersive $x$-ray (EDX) analysis to determine the elements present in the samples.

\section{Data Analysis}

From the measured data the following parameters will be computed:

* excess-air ratios

* $\mathrm{Ca} / \mathrm{S}$ mole ratios

* carbon conversion efficiency

* sulfur capture efficiency \%

* $\mathrm{SO}_{2}$ emissions levels in $1 \mathrm{~b} / 10^{6}$ Btu

* carbon balances 


\section{RESULTS AND DISCUSSION}

A major portion of this quarter was utilized to bring the equipment on-line as it had not been used for some time. The $\mathrm{CO}, \mathrm{CO}_{2}, \mathrm{O}_{2}, \mathrm{SO}_{2}$ and $\mathrm{NO}_{\mathrm{x}}$ analyzers were checked and a problem discovered with the $\mathrm{SO}_{2}$ analyzer. Troubleshooting of the problem followed and the defect was rectified without sending the instrument in for servicing to the manufacturer. The condition of the distributor plates in the main portion and circulating part of the bed were checked by dismantling the appropriate sections and reassembling them with new gaskets. The in-bed cooling water tubes for maintaining effective bed temperature control were modified so that the water supply through them could be more accurately controlled to secure finer control of bed temperature.

In previous tests, a problem was encountered with the gas sampling lines with the sampling line and filter getting clogged during prolonged sampling periods. To overcome this problem, the gas sampling probe at the exit of the particle collection multiclone system was fitted with an air flushing system, such that a constant flow of air is maintained into the probe when the combustion gases are not being sampled for analysis. This ensures that the off-take port of the gas sampling probe will be clean at all times.

A 1 imestone feeder manufactured by Accu-Rate Corporation has been installed and a supply of air hooked up to it, so that the limestone can be injected directly into the bed. Since the coal and limestone feeders operate independently, coal and limestone feed rates can be set individually.

Samples of standard coal have been secured. The coal has been crushed and sieved to $-14+35$ mesh. Agricultural grade limestone has been purchased and sieved for the tests to the same size for feeding into the bed with the coal. Some of the limestone has also been sieved to $-14+18$ mesh for use as a bed material. In addition, some river sand has been obtained and sieved to $-14+18$ mesh also for use as a bed material. A coal-slurry holding tank with a stirrer installed within it has been secured and installed. A variable-speed peristaltic pump has also been installed for pumping the slurry fuel into the fluidized bed combustor through a water cooled pneumatic injection system.

Shake-down combustion tests have been conducted in the circulating fluidized bed system. The propane preheat system has been fired and the fluidized bed brought up to temperature for coal injection which is about $1000^{\circ} \mathrm{F}$. Coal has been injected and the system brought up to operating temperatures of 1500 $1550^{\circ} \mathrm{F}$.

Presently experiments are being conducted to establish baseline data with the standard coal. Due to some delays experienced during startup, such as the malfunctioning of the $\mathrm{SO}_{2}$ analyzer, data are being gathered as of this writing and were not available to be included in this quarterly report. However, at the present time, preliminary tests have established that all items of equipment are functioning properly and baseline tests with standard coal are being conducted.

Samples of beneficiated slurry fuel from ISGS are also expected to be received shortly. Tests with the slurry fuel will be conducted as they become available. 


\section{CONCLUSIONS}

During this first quarter of the project, progress has been made to bring the circulating fluidized bed system on line, and in readiness for the fuels testing program. At the time of writing, tests are being conducted on the standard IBCSP No. 5 coal. These tests are to be accomplished during December and January. Tests on the coal slurry fuel are projected to be conducted soon after.

\section{DISCLAIMER}

This report was prepared as an account of work sponsored by an agency of the United States Government. Neither the United States Government nor any agency thureof, nor any of their employees, makes any warranty, express or implied, or assumes any legal liability or responsibility for the accuracy, completeness, or usefulness of any information, apparatus, product, or process disclosed, or represents that its use would not infringe privately owned rights. Reference herein to any specific commercial product, process, or service by trade name, trademark, manufacturer, or otherwise does not necessarily constitute or imply its endorsement, recommendation, or favoring by the United States Government or any agency thereof. The views and opinions of authors expressed herein do not necessarily state or reflect those of the United States Government or any agency thereof. 


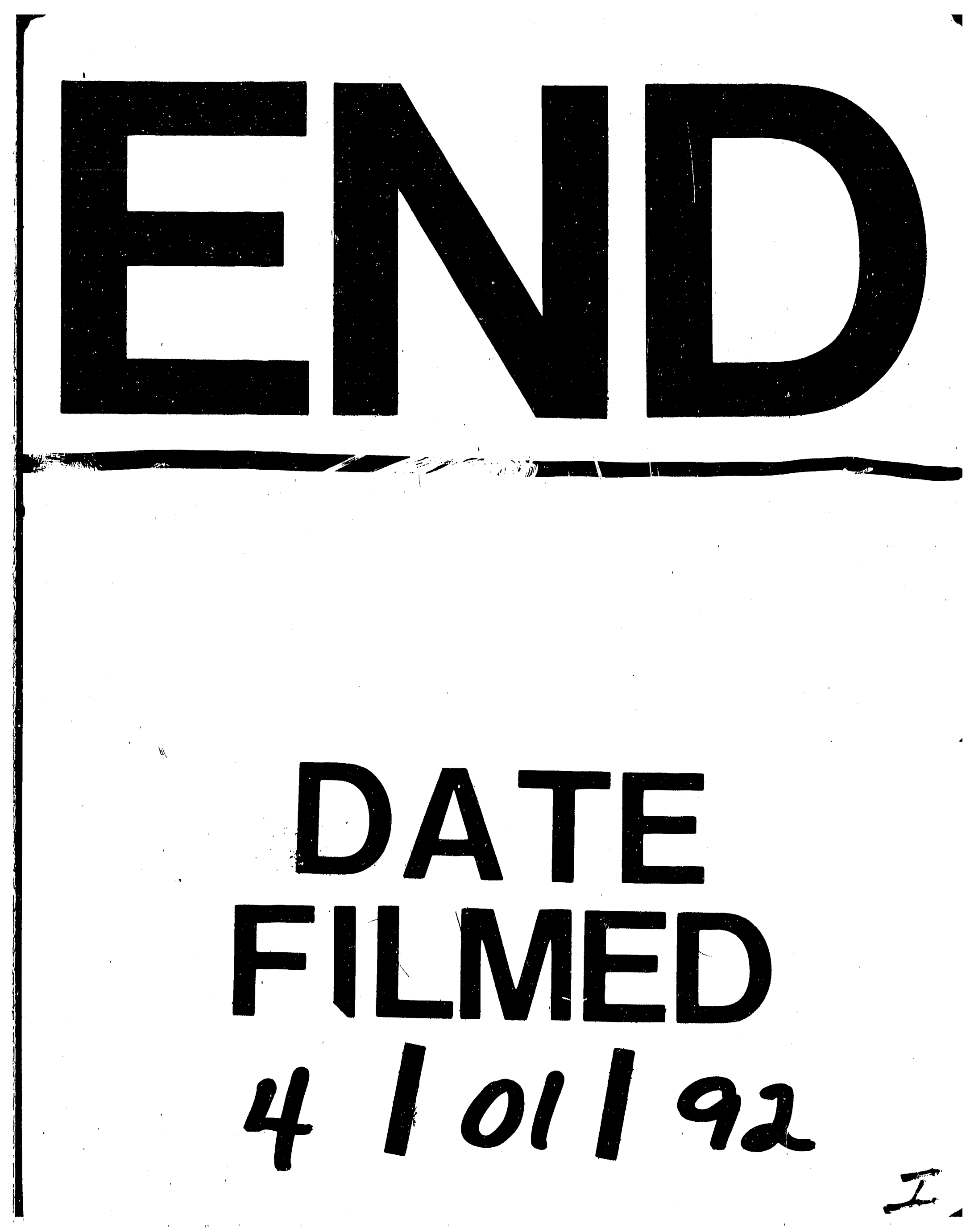




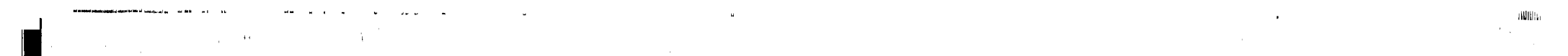

m 